\title{
EDITORIAL: 2011 Año Internacional de los Bosques
}

El pasado 21 de marzo se celebró el día forestal mundial, una fecha muy señalada y que sin embargo ha sido eclipsada por la magnitud de los múltiples problemas de trascendencia mundial que nos están afectando los últimos meses, hasta el punto de que haya pasado inadvertida para gran parte de la sociedad. Sin embargo ese día debiera constituir un momento de reflexión sobre la importancia que los bosques tienen como sustentadores de la vida en nuestro planeta y de los grandes beneficios que comportan a la humanidad. Los bosques constituyen un extraordinario patrimonio natural que es de todos y que necesariamente debiera ser objeto de atención, no sólo de los programas de organizaciones no gubernamentales, sino de los gobiernos y sociedad en general, como consecuencia de la creciente amenaza que se cierne sobre ellos debido a la continuada pérdida de fronteras forestales.

Por este motivo, el año 2011 fue declarado por la Organización de las Naciones Unidas como el Año Internacional de los Bosques. No es la primera vez que estos ecosistemas son protagonistas de los programas de un año internacional, ya que también 1985 se declaró como "Año Internacional del Bosque" a propuesta de la Organización de la Naciones Unidas para la Agricultura y la Alimentación (FAO), como consecuencia de la constatación de la alarmante reducción de la superficie forestal en todo el mundo. Ya entonces este organismo solicitaba que todos los países tomasen conciencia de la situación de estos medios para poner en marcha programas para su protección.
En un momento histórico como el actual, en que la población mundial de nuestra especie se acerca a los 7.000 millones de individuos, el 31\% de la superficie terrestre son tierras forestales, lo que equivale a unas 3.900 millones de hectáreas totales de bosque (FAO 2011). Esta cifra, aunque puede parecer relevante, tan sólo supone la mitad de lo que ocupaba hace unos 8.000 ańos (WWF 2011).

Esta creciente reducción de superficie forestal ha sido cifrada por la FAO, en el ańo 2010, en trece millones de hectáreas anuales, lo que equivale a una superficie de aproximadamente igual a la cuarta parte de la península Ibérica. Durante los últimos diez ańos hemos asistido a la pérdida de 93,9 millones de hectáreas de superficie forestal, lo que equivale a unos 5,6 millones de campos de fútbol al año. Desde finales del siglo XX se han transformado de manera irreversible superficies de bosque en plantaciones agrícolas, biocombustibles y cultivos forestales a un ritmo de 16,1 millones de hectáreas al año y de ellas el $94 \%$ de las transformaciones se han producido en zonas tropicales (WWF 2011). Se trata de una creciente deforestación que finalmente es responsable de la generación de cerca del $20 \%$ de emisiones de CO2 y otros gases invernadero, así como de la pérdida continuada de biodiversidad que se cifra según la Unión Mundial para la Naturaleza en la desaparición de unas 100 especies diarias como consecuencia de este proceso (IUCN 2011).

Estas evidencias llevaron a que el actual presidente de la Asamblea de la ONU, Joseph Deiss, indicase durante su intervención en el acto de inauguración 
del Año Internacional de los Bosques 2011: “Centenares de millones de personas, fundamentalmente en los países en desarrollo, dependen de los bosques para su vida cotidiana, son el pulmón del planeta; sin embargo, cada minuto que pasa desaparecen unas 25 hectáreas de bosque".

Más de 1.600 millones de personas dependen directamente de los bosques, siendo la base de su subsistencia (ONU 2011).

Como ejemplo podemos citar la selva amazónica en la que viven 300 grupos indígenas y 30 millones de personas, un bosque que constituye la masa forestal más importante del mundo con una extensión de unos 7 millones de kilómetros cuadrados y que es considerado como el pulmón verde de nuestro planeta y que ha visto reducida su superficie en un $17 \%$ en los últimos 50 años.

Tenemos una urgente necesidad de reconocer de manera decidida la importancia que para la vida en el planeta y el desarrollo de nuestras sociedades tienen los bosques. El interés en su conservación no reside tan sólo en el interés por mantener la biodiversidad que encierran, algo totalmente justificable en sí mismo, sino también por los elevados eco-servicios que prestan, siendo su conservación una garantía de mejora de las condiciones de vida de las poblaciones humanas. Los bosques juegan un papel imprescindible en términos de mitigación y adaptación al cambio climático, captura de agua y generación de recursos hídricos, protección contra eventos catastróficos por fenómenos naturales como los corrimientos de terreno e inundaciones, entre otros. Los servicios ambientales que prestan a la humanidad se estiman en 720.000 millones de dólares anuales (UICN 2011), sin incluir beneficios directos como la explotación de madera, una industria que mueve unos cien mil millones de dólares anuales, ni considerar el valor potencial de explotación sostenible de especies animales y vegetales que viven en estos medios. Los bosques son productores de alimentos, medicamentos, combustible, energía, fuentes de ingresos y empleo para personas de las comunidades más pobres en el mundo, habiéndose valorado en 130.000 millones de dólares por año los beneficios aportados (UICN 2011).

Las cuestiones éticas o estéticas para conservar esta biodiversidad son importantes, pero pensemos también en un mundo con un crecimiento poblacional exponencial en el que existen amplias regiones sumidas en la más absoluta pobreza. Los beneficios que para la humanidad comportan los bosques y las oportunidades que nos ofrecen de integrar las políticas de conservación en los programas de cooperación, decididamente debieran ser aspectos que hagan reflexionar a los gobiernos y a toda la sociedad en este Año Internacional de los Bosques. La contribución de los bosques al bienestar de la humanidad y los enormes retornos de las inversiones destinadas a proteger estos ecosistemas son aspectos a tener en cuenta en el marco de las políticas de impulso al desarrollo sostenible y lucha para la reducción de la pobreza. Como ha señalado Stewart Maginnis, director del programa de Conservación de Bosques de la UICN, "El manejo local de los bosques es una inversión pública y una opción de asistencia al desarrollo sumamente rentable".

Finalmente, adquiramos un compromiso cuando compremos productos derivados de la madera. Pensemos en los bosques y exijamos el certificado forestal internacional FSC (Forest Stewardship Council o Consejo de Administración Forestal). Este certificado asegura que el producto de origen forestal que adquirimos, permite mantener la biodiversidad, la productividad y los procesos ecológicos de los bosques, a la vez que contribuye al desarrollo socioeconómico de las poblaciones locales a través de una gestión forestal sostenible y económicamente rentable (FSC -Forest Stewardship Council)

Eduardo Galante

Director del CIBIO 